\title{
El papel de las emociones en la esfera pública: la propuesta de M. C. Nussbaum
}

\author{
The role of emotions in the public spbere: M. C. Nussbaum \\ proposal
}

JOSÉ MANUEL PANEA MÁRQUEZ

Departamento de Metafísica y Corrientes Actuales de la Filosofía, Ética y Filosofía Política.

UNIVERSIDAD DE SEVILLA

Artículo recibido: 26 febrero 2017

Solicitud de revisión: 22 de junio 2017

Artículo aceptado: 19 septiembre 2017

Resumen

¿Cómo pueden las emociones favorecer una sociedad democrática más justa y estable? El propósito de este artículo es destacar la importancia de las emociones en el pensamiento de M. C. Nussbaum, y cómo pueden contribuir, en el contexto del liberalismo político, a reforzar y dar estabilidad a la democracia.Todo ello parece exigir, según Nussbaum, integrar el papel de las emociones en el proyecto educativo de la sociedad, para superar el modelo de justicia centrado en el beneficio mutuo, ampliándolo con otro, cuyo centro de gravedad serían las capacidades y el desarrollo humano. Y en tal sentido, es necesario preguntarse por el papel que han de jugar las humanidades, para dar viabilidad y continuidad a tal proyecto.

Palabras clave: Nussbaum, emociones, democracia, justicia y humanidades.

\begin{abstract}
How can emotions enable a fairer and more stable democratic society? The aim of this essay is to emphasize the importance of emotions in M.C. Nussbaum's thought and how can they contribute to reinforce democracy and provide it with stability to in the context of political liberalism. All of this seems to require, according to Nussbaum, the integration of the role of emotions in society's educational project, so as to go beyond the model of justice focused on the mutual benefit, widening it with another, whose centre of gravity would be the capacities and the human development. In this sense, it is necessary to ask ourselves about the role Humanities should play, so as to provide such a project with feasibility and continuity.
\end{abstract}

Key words: Nussbaum, emotions, democracy, justice and humanities. 


\section{EMOCIONES POLÍTICAS, LITERATURA Y FILOSFÍA}

Nussbaum ha insistido en que no basta el PIB para medir el desarrollo ni la calidad de vida (Nussbaum, 2014b: 147). Junto a Amartya Sen, aunque con una perspectiva diferente (Nussbaum, 1997b: 296; 2003; Tienda, 2011: 193-204; Monereo, 2015: 108), propondrá que además de los factores estrictamente económicos es preciso tomar buena cuenta de las capacidades humanas y el modo en que se fomentan o no en la sociedad, pues solo así estaremos realmente en condiciones de medir su aptitud para el desarrollo humano (Nussbaum, 1996: 15-23; 2007b: 88-89). Porque no se trata de enfocar los problemas políticos como si solo nos debiera preocupar el aumento de productividad o la riqueza nacional, pues no será suficiente formar ciudadanos productivos, sino que, en no menor medida, necesitaremos ciudadanos que sean capaces de convivir con otros, a pesar de las diferencias filosóficas, políticas o religiosas que, inevitablemente, habrá entre ellos. Educar en el respeto a la libertad y en la igualdad, así como en la solidaridad, asumiendo las diferencias, resultará ser de capital importancia en las sociedades actuales, cada vez más multiculturales, y también social y económicamente más heterogéneas (Nussbaum, 2010; 2013). Y es en este contexto, reconociendo, como diría Rawls, el hecho del pluralismo, y con un concepto nuevo de desarrollo, más allá del meramente economicista, en el que Nussbaum se preguntará qué puede aportar la filosofía y también la literatura en el cultivo de una ciudadanía más sensible y crítica (Nussbaum, 1995a). Porque, nos dirá, Sófocles en la antigüedad clásica, lo mismo que Dickens y W. Whitman en la contemporánea, por citar algunos ejemplos, tendrían un papel fundamental en la conformación de esa ciudadanía democrática, crítica y solidaria, que hoy tanto necesitamos, para procurar el mantenimiento de sociedades en cuyo punto de mira esté no meramente el incremento de la productividad y del beneficio, sino un verdadero desarrollo humano, como núcleo fundamental de un nuevo modelo de justicia (Nussbaum, 1995b: 129-133).

En la concepción de Nussbaum, la literatura nos abre a la conciencia de nuestra humana «finitud y vulnerabilidad», porque todos, sin excepción, estamos expuestos a la desgracia y a la muerte.Y de aquí la importancia de favorecer la «compasión», entendida como una emoción dolorosa orientada hacia el sufrimiento grave de otra criatura (Nussbaum, 2014b: 175), como pilar esencial en su proyecto de justicia, inspirador de una auténtica con- 
vivencia integradora y de concordia (Nussbaum, 2014: 167-175; 197-202). ${ }^{1}$ La experiencia trágica que propician las obras de Esquilo, Sófocles o Eurípides, lejos de transmitir la idea de resignación ante lo inevitable, nos recuerda los límites que cercan toda humana acción, y fomenta la conciencia trágica y la responsabilidad por las acciones (Nussbaum, 2014b: 321). Cultivar la imaginación literaria facilitará el ponernos en la piel del otro, por lo que no solo no será contraria a la discusión racional, sino que nos proporcionará ingredientes esenciales y necesarios para la misma. De aquí que Nussbaum se interese en cómo podríamos reproducir esta experiencia en nuestras democracias (Nussbaum, 2014b: 335-374). Y considera que el papel educativo que en los festivales clásicos jugaron las tragedias pueden desempeñarlo hoy obras como Tiempos difíciles, o David Coperfield, pues está convencida de que la lectura de obras de este tipo contribuirá a la formación de una ciudadanía más lúcida y más sensible a los problemas humanos (Nussbaum, 1995a: 46; 2014b: 316-321).

Y, por otra parte, esta defensa de la imaginación literaria, y de las obras clásicas y contemporáneas, no implicará que ya no necesitemos del análisis teórico o filosófico en cuestiones de teoría moral y política, ni que asistamos a un debilitamiento de la filosofía en favor de la literatura, al modo de R. Rorty. Antes al contrario, los argumentos filosóficos serán absolutamente imprescindibles para debatir con rigor sobre ideas relativas a la justicia social, y discutir minuciosamente sobre los modelos propuestos. Literatura y filosofía resultan, por tanto, imprescindibles y complementarias (Tienda, 2011: 146-156), pues si la teoría nos proporciona una concepción de la justicia, el universo literario, al cultivar la imaginación, la empatía y la compasión, jugará un papel nada desdeñable en su realizabilidad. Por lo que si, por una parte, las obras literarias proporcionan contenidos interesantes para la construcción de teorías morales y políticas, también favorecerán el desarrollo de capacidades morales, sin las cuales aquellas carecerían de efectividad (Nussbaum, 1995a: 47-48). Así, considera Nussbaum que el lector acabará implicándose en la historia novelada de tal modo que la evaluará crítica y afectivamente. Además, la imaginación nos ayudará a saber reconocer en nuestro propio mundo situaciones similares, lo que nos permitirá también elegir de manera más reflexiva en él. La novela incorpora, en suma, un compromiso tal hacia la riqueza del mundo interior, que resultará también imprescindible en la construcción de la vida pública, en la que volverán a reproducirse, mutatis mutandis, situaciones similares. Y

1 Entre otros, remando en la misma dirección, aunque con planteamientos distintos, han insistido Conill (2009) y Cortina (2010). 
en nuestras manos estará que sucedan o no cosas como las que en dichas novelas se nos narran (Nussbaum, 1995a: 61-62, 77).

\section{LAS EMOCIONES Y EL FLORECIMIENTO HUMANO}

Las emociones comportan evaluaciones sobre «objetos externos» relevantes para nuestro bienestar, por lo que muestran nuestra naturaleza necesitada e incompleta frente al mundo, ${ }^{2}$ y aquello que está fuera de nuestro control (Nussbaum, 2008: 41-42). Además, el objeto de la emoción es visto como importante para la propia vida de la persona. Y por ello, las emociones parecen tener un carácter eudaimonista, es decir, que tienen que ver directamente con el florecimiento del sujeto que las encarna (Nussbaum, 2008: 53-54).

Pero las emociones integran, además, y de un modo esencial, nuestra estructura cognitiva. Por descontado, pueden ser, como las creencias, verdaderas o falsas, justificadas o injustificadas, razonables o irrazonables (Nussbaum, 2008: 68-69). Porque ocurre que, a menudo, el sentido que las personas tienen de lo que es importante y valioso resulta ser confuso y desordenado, y no está en la línea de sus creencias éticas reflexivas. Esto nos permite recordar que las emociones tienen una referencia ineludible al «yo», y que constituyen «nuestro» esquema de objetivos y proyectos, por lo que incorporan juicios evaluativos, además de encarnar procesos corporales (Nussbaum, 2008: 74-81), de tal manera que el cambio en las creencias implicará un cambio en las emociones. ${ }^{3}$ En cualquier caso, parece que además de contener pensamiento evaluador eudaimonista, las emociones están esencialmente conectadas con la imaginación y con la representación de acontecimientos en ella.A tal respecto, en la formación del juicio, la imaginación aportará tanto como los pensamientos eudaimonistas (Nussbaum, 2008: 88-89).

Por otra parte, es bien sabido que las emociones no emergen en el yo, o en los contextos sociales, por generación espontánea, sino que siempre tienen una historia detrás, individual y colectiva, en gran parte socialmente construida. Su contenido cognitivo viene, pues, envuelto en una historia narrativa compleja, y dicha historia es clave para dar cuenta de las emocio-

2 Para el estudio detallado de las emociones como juicios de valor, así como para la relación entre biología y cultura en el ser humano, en la perspectiva nussbaumsiana, remitimos a Tienda (2011: 59-112) y Gil (2016a; 2014: 89-98).

3 Tesis que pretende defender apoyándose en Aristóteles, pero que ha suscitado un interesante debate al respecto (Trueba, 2009b: 159-170). 
nes mismas (Nussbaum, 2008: 209-211). De aquí la importancia de su cuidado y cultivo, tanto en el plano individual como en el colectivo: tal será uno de los pilares fundamentales de la propuesta nussbaumsiana, frente a los que presentan un enfoque meramente político de los problemas sociales. En tal sentido, su proyecto, si bien se entronca en la tradición del liberalismo político de J. Rawls, viene a completarlo y mejorarlo, desde una perspectiva esencial tanto para el florecimiento personal, como para la estabilidad política (Di Tullio, 2013; Nussbaum, 2003: 50-56; 2011). Y es a partir de esta perspectiva cuando se les reconocerá a las emociones políticas un protagonismo fundamental (Nussbaum, 2007b: 182-184; 2014b).

No se le escapa a Nussbaum que las emociones, junto a su centralidad para el florecimiento humano, presentan una ambivalencia innegable, pues pueden causar serios problemas a la vida moral, al mismo tiempo que ofrecen recursos sin los cuales nuestra vida sería drásticamente incompleta (Nussbaum, 2008: 234-35). Sin embargo, saber gestionarlas bien no implicará, como lo entendió Kant, que haya que levantar una especie de muro de contención para frenar su empuje, sino más bien cambiar nuestra mirada y el modo en que evaluamos, transformando las emociones que sostienen dicha evaluación (Nussbaum, 2008: 268-271).

Las emociones tienen, pues, una estructura narrativa cuya historia es imprescindible conocer para su comprensión. Y, en este sentido, la aportación de la literatura y de las artes, sostendrá Nussbaum, resultará esencial en la hermenéutica del yo y de los otros (Nussbaum, 2001; 2008; 2010). Al penetrar imaginativamente en el interior de una historia, aprendemos a comprender al otro y a nosotros mismos de otro modo (Nussbaum, 2001; 2010; 2014b; Tienda 2011; Gil, 2016b).Al mismo tiempo, puede contribuir a que las personas modifiquen el modo de ver a las otras personas, de una manera no instrumental, ni eudaimonista, sino como dignas en sí mismas. Finalmente, la narración puede atajar el sentimiento de vergüenza originaria, propio de todos los seres humanos, al analizar la vida de hombres, tan imperfectos y vulnerables como nosotros (Nussbaum, 2008: 273-274; 2014b).

Un buen ejemplo de lo que queremos decir lo constituyen las tragedias clásicas. La tragedia antigua nos muestra lo que Aristóteles llamaba lo compasible y lo temible, pues representa a personas buenas que sufren grandes dolores sin que medie por su parte ningún fallo, y por eso son susceptibles de compasión. Pero al mismo tiempo, nos permiten vernos a nosotros mismos como vulnerables y como víctimas posibles de sufrimientos futuros inesperados (Nussbaum, 2008: 275-276; Trueba, 2004). 
Sin duda alguna, el contenido emotivo de la obra guardará una estrecha relación con la forma y, además, al tratarse de un texto artístico y no de un tratado científico, su estructura admitirá lecturas diferentes en profundidad (Lotman, 2011) y también en las relaciones posibles que quepa establecer entre la propia vida del lector y el texto, por lo que no podemos hablar de «la lectura» o de «la experiencia correcta». Pero lo importante es, como decía Proust, que la obra se convierte en un «instrumento óptico» mediante el cual el lector puede enfocar ciertas realidades personales, de manera que el espectador-lector lee o interpreta, pero al mismo tiempo lo que hace es leer el mundo y a sí mismo (Nussbaum, 2008: 278-279).

En suma, la comprensión del sufrimiento ajeno, y de que todos estamos expuestos al dolor, supondrá alcanzar una verdad inequívoca sobre nuestra vida humana, la cual nos protegerá frente al sentimiento áspero y arrogante de la mera autosuficiencia, que puede echar a perder nuestro trato con los demás en la vida:

Como señala Aristóteles, si alguien tiene una «disposición desmesurada», una bybristikè diáthesis, no sentirá compasión. Las tragedias conforman un espectador que no tiene una bybristikè diáthesis, que está abierto a las experiencias emocionales que tienen que ver con el sufrimiento de los demás y que, por tanto (y siendo todo lo demás igual), está un poco mejor preparado para relacionarse con los otros seres humanos sobre la base de la reciprocidad (Nussbaum, 2008: 280).

En efecto, como el ser humano es un animal político, también las emociones humanas serán éticas y políticas. Y de aquí que resulte crucial que nos preguntemos por el papel que desempeña la sociedad en la construcción de estas, y viceversa. Porque la cultura constituye un componente determinante en las emociones del individuo. Pero no menos importante será el hecho de que compartimos una humanidad común, igual que una biología común, lo que contribuirá a que las obras de Sófocles o de Eurípides traspasen las barreras culturales. Y ello es lo que posibilita que dichos textos aborden mitos de pérdidas y conflictos familiares tales que resultan fácilmente reconocibles para otras culturas (Nussbaum, 2008: 179-181).

Sin duda, el hecho de que seamos partícipes de una humanidad común es lo que da sentido a la propuesta nussbaumsiana sustentada en su cosmopolitismo bumanista de corte estoico (Nussbaum, 1999, 22-29; Trueba 2009a; Benéitez, 2010). El hombre vive inmerso en una cultura propia, sin duda, pero también es ciudadano del mundo, en el sentido de que comparte anhelos, miedos, capacidades y limitaciones con todos los hombres, expuestos, sin excepción, al deterioro, al sufrimiento y a la muerte. Al mismo tiempo, este yo inmerso en una cultura es capaz de distanciarse libre y 
críticamente de ella. Por lo que, sin negar nunca la importancia de lo social en la formación del yo, Nussbaum calibrará su influencia, excesiva en los autores de la «construcción social», como M. Foucault (Nussbaum, 2008: 200). Sin negar, pues, el peso de lo social, llamará la atención sobre el potencial de variedad y libertad individuales, y sobre la capacidad que tiene el yo de reflexionar críticamente sobre su propio concepto de florecimiento humano. Y es aquí donde las emociones que entren en liza jugarán un papel central: «El hecho de que los seres humanos deliberen éticamente sobre cómo vivir supone que las emociones son una parte fundamental de la deliberación moral» (Nussbaum, 2008: 201). Las mismas emociones pueden ser evaluadas, y de alguna manera, alteradas, si no superan la crítica. Y en la formación de las emociones, antes que se produzca la «construcción social», la interacción del niño con sus familiares y cuidadores también resultará ser de una importancia fundamental (Nussbaum, 2008: 202-203).

\section{EMOCIONES Y DELIBERACIÓN: LA COMPASIÓN COMO GUÍA}

Le interesa a Nussbaum saber qué contribución positiva hacen las emociones como tal a la deliberación moral, tanto personal como pública. Por ello, aunque seguirá a los estoicos, en cuanto a su idea de las emociones como juicios de valor, sin embargo no compartirá su tesis normativa de que las emociones son siempre malas guías y deben ser completamente eliminadas de la vida humana (Nussbaum, 2008: 336; 2003a: 447-495). Hay emociones que expanden las fronteras del yo, mientras que otras establecen fronteras en torno suyo, como será el caso del narcisismo (2014b: 198212), o del asco y de la vergüenza (Nussbaum, 2006: 243-261; Gil, 2013). Y si los estoicos defendían la apatbeia, la impasibilidad del sabio, liberado de su influjo, Nussbaum quiere proponer una ética en la que aquellas tengan un papel positivo como guías (Nussbaum, 2008: 339).

En la vida humana, las ocasiones para mostrar compasión, como nos dirá Aristóteles, son múltiples: la muerte, la agresión corporal, los maltratos, la vejez, los reveses de la fortuna o de las expectativas, o la mera ausencia de buenas perspectivas (Nussbaum, 2008, 346). Pero siempre serán circunstancias graves, lo que Aristóteles denomina «de magnitud», y que quien las padezca no las merezca (Aristóteles, 1990: 1385b13). No obstante, Nussbaum nos advertirá de que la compasión, por noble que sea, no está 
exenta de riesgos. ${ }^{4}$ Su objeto es intencional, interpretado en el marco valorativo de quien la experimenta, que pueda estar equivocado respecto de lo que en realidad ocurre. Por ello, nos recordará que el juicio que se forma el espectador siempre será falible (Nussbaum, 2008: 349-350).

Sin duda, se nos plantea el difícil problema de cómo la ficción puede llegar a transformar al yo en alguien capaz de compadecerse realmente por la suerte del otro. ${ }^{5} \mathrm{Y}$ en tal sentido, parece que tienen que darse ciertas condiciones para que brote la compasión. Tanto Aristóteles, como luego Rousseau, admitirán que para que exista compasión las personas deben reconocer previamente que sus posibilidades y su vulnerabilidad son parecidas a las del que sufre. Esto es lo que la hace especialmente interesante. Y por ello, lo más necesario sería llegar a entender, de algún modo, que las penurias de la otra persona podrían interpretarse en clave del propio florecimiento - juicio eudaimonista. En síntesis, es importante recordar que, a juicio de Nussbaum, la compasión incorpora tres elementos cognitivos fundamentales: el juicio de la magnitud; el juicio del inmerecimiento, y el juicio de las posibilidades parecidas como auxilio heurístico para formar el juicio eudaimonista (Nussbaum, 2008: 355-361).

No obstante, no hay que confundir compasión con empatía, pues esta solo implica la reconstrucción imaginativa de la experiencia del que sufre, por lo que no bastará para que haya compasión, siendo moralmente neutral. Aunque también es cierto que este ejercicio mental hará más difícil que neguemos su humanidad a aquellos con cuyas experiencias habríamos conseguido establecer empatía. Y por eso, los nazis hicieron todo lo posible por devaluar a los judíos, a los que se referían con la expresión Untermenschen, subhumanos (Jahanbegloo, 1993). ${ }^{6}$ Precisamente, la humillación sistemática bloqueó la aparición de la compasión. Y esta «avería en el me-

4 Entre otros, son destacables los estudios de Arteta (1996) y Mèlich (2010) sobre el vínculo entre mortalidad (o finitud), dignidad y compasión, considerada como una virtud de carácter reflexivo y activo (Arteta, 1996: 253-289).

5 Es el problema de la paradoja de Radford (1975), de cómo podemos conmovernos ante la ficción, sin duda un tema interesante y complejo (Scruton, 1974; Walton, 1978a, 1978b; Boruah, 1988; Bejarano, 1995)

6 Por ello, I. Berlin consideraba que los nazis no eran locos, ni tampoco idiotas morales, como pensaba Arendt (Arendt, 2003), sino que, premeditadamente, habían organizado todo un cuerpo de creencias y emociones, forjando falsedades monstruosas, que oradores y escritores enseñaban sistemáticamente. De aquí que para prevenir el mal que hacen los fanáticos no solamente haya que comprender las raíces psicológicas desde las que actúan, sino también sus raíces intelectuales, y combatirlas, sacando a la luz sus mentiras, que pretenden pasar por verdades, y así dejarles en evidencia, tratando de mostrarles que están equivocados (Jahanbegloo, 1993: 59-60). No es de extrañar que el propio Berlin reconociera que no guardaba mucha simpatía ni admiración por la obra de Arendt (Jahanbegloo, 1993: 111). 
canismo mental» condujo a la negación moral de la condición humana del judío, lo cual hizo que muchos alemanes terminaran por llevar una auténtica doble vida (Nussbaum, 2008: 366-375).

\section{LA COMPASIÓN Y LA VIDA PÚBLICA}

Nussbaum ha afirmado que no es como utilitaristas económicos, sino como lectores de novelas, como deberíamos aproximarnos a las opciones sociales que disponemos, tratando de considerar a nuestros conciudadanos con el asombro y la generosidad que esta imaginación promueve (Nussbaum, 1995a: 77). Se plantea así el problema: «¿Cómo puede cultivar la compasión la cultura pública de una democracia liberal, y hasta qué punto podría basarse en esta motivación, que se sabe falible e imperfecta?» (Nussbaum, 2008: 445). En otros términos, Nussbaum se propone examinar el lugar de la compasión en el marco del liberalismo político (Nussbaum, 2014: 175-180), siguiendo en esto a Rawls, capaz de dar cabida a un consenso entrecruzado entre ciudadanos, con concepciones del bien muy diferentes, siempre que sean razonables, en lo relativo a lo que Rawls denominaba «la estructura básica de la sociedad», es decir, a un orden constitucional elemental, y al esquema básico de instituciones y derechos (Nussbaum, 2002; 2007b). Y en esta estructura básica de la sociedad, el papel de las emociones será fundamental, porque necesitamos, como sugería Rawls, una «psicología política razonable», es decir, no someter a la psicología humana a tensiones insostenibles. Pero no será menos perentoria la motivación de la ciudadanía respecto a dicho proyecto, para garantizar una aprobación amplia y dotarlo de la estabilidad suficiente (Nussbaum, 2008: 446-448). Y es precisamente aquí donde insistirá en el insoslayable papel de las humanidades, y cómo estas contribuyen al fomento de la actitud socrática. En otras palabras, desde esta perspectiva se entiende perfectamente por qué la democracia necesita de las humanidades como eje vertebrador suyo (Nussbaum, 2010: 51-74).

Expresado en otros términos, y valiéndose también del ejemplo de $\mathbf{W}$. Whitman, Nussbaum considera que determinadas emociones pueden y tienen que conformar la base para la cultura pública de una democracia plural. Se trata, pues, de preguntarse cómo promover una compasión apropiada en el marco de instituciones liberales y democráticas. Por consiguiente, la compasión debería ser abordada tanto en el plano de la psicología individual, como en el de los proyectos institucionales. En efecto, la 
imaginación compasiva puede jugar un importante papel a la hora de determinar las necesidades humanas de los bienes primarios, y en la elección de los principios distributivos más elementales de la rawlsiana «posición original». Pero también puede irse plasmando en la legislación concreta, a medida que se detallen cuestiones relativas al bienestar, a la desigualdad humana, o si nos preguntamos sobre los deberes de las naciones más ricas sobre las más pobres (Nussbaum, 2008: 445-447).

Así pues, los ámbitos educativo e institucional resultarán ambos de extrema importancia. Y ello porque aun cuando llegaran a existir instituciones excelentes, siempre tendrán que ser respaldadas por personas:

\footnotetext{
Debemos, por tanto, confiar en individuos compasivos que mantengan con vida y ante nuestra vista las nociones políticas esenciales. Los sistemas políticos son humanos, y sólo son buenos si se mantienen vivos en un sentido humano. Si producimos un bienestar social excelente pero poblado por ciudadanos inertes, obedientes y del todo sometidos a la autoridad, esto constituirá un fracaso independiente de lo bien que funcione dicho sistema. No se demostraría estable; y tampoco podría lograr el fin de toda sociedad política, a saber, capacitar a los ciudadanos para que persigan una vida buena (tanto dentro como fuera de la esfera política) a su manera (Nussbaum, 2008: 448).
}

La compasión adecuada es necesaria no solo en el ejercicio de la justicia -en jueces y jurados - sino también para atender con interés las necesidades de nuestros conciudadanos, por lo que resultará esencial en la elaboración de una concepción política y en la educación. Y por ello, la relación entre compasión e instituciones es una suerte de camino de ida y vuelta: los individuos compasivos las crean, y estas, a su vez, participan en la gestación y desarrollo de la compasión en los individuos. En este sentido, las instituciones tendrán una extraordinaria tarea que realizar, tanto a la hora de fomentar emociones positivas - tal es el caso de la compasión adecua$\mathrm{da}-$, como de disuadir aquellas otras que la impiden, como el narcisismo, la intolerancia, la vergüenza, la envidia y el asco (Nussbaum, 2006: 365-395; 2008: 392-393, 449).

\section{LOS LÍMITES DEL CONTRACTUALISMO: EMOCIONES, CAPACIDADES Y UN NUEVO MODELO DE JUSTICIA}

El problema que se le planteará, pues, a Nussbaum es cómo en una democracia liberal constitucional se pueden promover juicios adecuados y emociones adecuadas. Habrá que preguntarse también qué «bienes externos» son verdaderamente importantes y hasta qué punto lo son. Y la res- 
puesta tendrá que venir dada por las múltiples concepciones del bien que los ciudadanos alberguen, ya sean seculares o religiosas (Nussbaum, 2008: 460). Sin embargo, para Nussbaum es preferible afrontar el problema de los derechos básicos de una sociedad política liberal, entendiéndolos como un conjunto de capacidades y oportunidades de funcionamiento de toda persona (Nussbaum 2002: 115; 2007b: 141-176; 2008, 461).Y todas las sociedades deberían garantizar a sus ciudadanos un nivel superior al umbral mínimo de estas capacidades. ${ }^{7}$

Como decíamos, la lista de capacidades debería estar garantizada al menos en un estándar mínimo (Nussbaum, 2007b: 174-177). Y no por casualidad, tal lista se corresponde con la enumeración que Sófocles y Aristóteles consideran que sería un trance trágico, pues la privación de ciertos derechos, especialmente importantes para los ciudadanos, resultaría particularmente trágica. En otras palabras, ciertas calamidades no solo serían graves, sino que podríamos decir que son injustas, por lo que nadie debería sufrirlas.Y tales desgracias podrán llevarnos, sin duda, al llanto y a la indignación, pero no a la resignación, pues deberíamos preguntarnos qué podemos hacer para reducir la probabilidad de que tragedias así se vuelvan a producir (Nussbaum, 2008: 463-464). Junto a la internacionalización de los problemas en un mundo cada vez más global, la idea kantiana de la dignidad humana universal estará también en el fondo de la propuesta de su humanismo cosmopolita, y le servirá de norte y guía (Nussbaum, 1999: 22-29). En efecto, vivimos en un mundo en el que todos dependemos de personas que jamás hemos visto y que, a su vez, dependen de nosotros. Los problemas económicos, ambientales, religiosos y políticos tienen alcance mundial, y la cooperación para su resolución es insoslayable. Baste con citar algunos ejemplos, como el calentamiento global, los regímenes de comercio internacional, la protección del medio ambiente, el futuro de la energía nuclear, los peligros de las armas nucleares, los problemas de los refugiados y de los flujos migratorios, la elaboración de normas laborales dignas, y la protección de la infancia frente al abuso sexual, la esclavización, y la trata de personas. Son todos ellos problemas que no pueden abordarse seria y responsablemente sin un diálogo en el ámbito internacional (Nussbaum, 2010: 113-114).

7 Se ha referido a ello en múltiples lugares. Resumidamente, serían las siguientes: vida; salud corporal; integridad corporal; sentidos, imaginación y pensamiento; emociones; razón práctica; afiliación; interés hacia otras especies; juego; control sobre el propio entorno, tanto político como material (Nussbaum, 2008: 461-463). 
Del mismo modo, insistirá Nussbaum en que una democracia liberal plural debería garantizar el respeto equitativo y el interés por todos los ciudadanos, sin distinción de raza, sexo, clase u origen étnico. Igualmente, debería mostrarse un mayor interés por el destino de los seres humanos, más allá de las fronteras nacionales, conscientes de que muchos de los problemas políticos son compartidos, y también requieren soluciones internacionales compartidas (Nussbaum, 2008: 466-467).

Por otra parte, no deberíamos perder de vista que las sociedades que articulan el contenido cognitivo de la compasión también han de hacer frente a otras emociones contrarias a ella, como la envidia, la vergüenza y el asco (Nussbaum, 2006; 2013; 2014b). Esto último, por ejemplo, se relaciona con el deseo humano de no querer aceptar nuestra animalidad, y tiene que ver con la misoginia, el antisemitismo y otra suerte de odios grupales. En tal sentido, nos dirá Nussbaum, el asco supone una contaminación imaginaria del yo, y de aquí que, como apuntábamos más arriba, los judíos, en la literatura nazi, fueran retratados como asquerosos, como insectos o bichos abyectos, Untermenschen (Jahanbegloo, 1993). Por contra, insistirá Nussbaum, una sociedad preocupada por la justicia debería divulgar imágenes positivas de las minorías, y asegurarse de que dichos grupos puedan gozar de confianza pública (Nussbaum, 2008: 469-470).

Lo mismo sucede con la vergüenza como emoción negativa. Se trataría de educar en la idea de que no hay nada vergonzoso en ser portadores de un cuerpo sometido a las vicisitudes del tiempo, el deterioro, la discapacidad y la enfermedad (Nussbaum, 2007b: 163-225; 2006: 323-364). Esto será fundamental para abordar problemas de dependencia, o de integración, en el caso de discapacitados mentales y físicos, que solicitan de nosotros que miremos la debilidad y la dolencia sin vergüenza ni asco, y que cuidemos de ella (Nussbaum, 2008: 471-472). Todo lo cual exigirá, pues, ensanchar una concepción de la justicia que se ha quedado en los insuficientes márgenes del modelo contractual, inspirado en el beneficio mutuo, y proponer un nuevo modelo de justicia basado en las capacidades y el desarrollo humano, que verdaderamente suponga la protección efectiva de los derechos humanos, más allá de la mera y bienintencionada declaración de principios (Nussbaum, 1997b; 2007b: 93-106).

Para lograr una práctica de la compasión racional, es decir, bien informada, será necesario acometer una educación moral y cívica, no solo en el ámbito de la vida privada familiar, sino también en el público. Y en tal sentido, la educación debería cultivar, en todos los niveles, la capacidad de imaginar las experiencias de los otros y de participar en sus sufrimientos. 
Y esto implicaría dar mayor importancia a las capacidades que el señor Gradgrind, el personaje de Dickens, en David Coperfield, consideraba como "vana fantasía»; o lo que es lo mismo, concederle un amplio espacio en la educación a las humanidades y a las artes, ya desde la escuela primaria, favoreciendo la creación de juicios correctos, y que los jóvenes vayan desarrollando tempranamente la capacidad de ampliar su empatía a más personas y tipos de persona. Pero a lo que estamos asistiendo hoy es, precisamente, a una paulatina marginación de las humanidades y las artes en la educación a todos los niveles. Y de aquí que insista Nussbaum, con firmeza, en su ineludible papel socrático para la formación de una ciudadanía crítica, pues en ello estará también en juego el futuro de la democracia (Nussbaum, 2010).Y, en tal sentido, el primer paso será evitar una ciudadanía roma y emocionalmente inerte, presa de la indiferencia o de los deseos agresivos (Nussbaum, 2008: 472-473).

Pero Nussbaum quiere dejar muy claro cuál es la posición que defiende: no el mero estudio erudito de la literatura y las artes, sino el cultivo de las emociones que ellas propician. Transformar nuestras emociones, nuestros juicios evaluativos y nuestras actitudes: tal será el cometido encomendado a las humanidades en general, y a la literatura en particular. Obras como Tiempos difíciles (Dickens), Las uvas de la ira (J. Steinbeck), Hijo nativo (R.Wright), y La cabaña del tío Tom (H. Beecher) nos ayudarán a remover obstáculos mentales para alcanzar una racionalidad política plena, en la que la emoción juegue un papel primordial. Sin embargo, esto es algo escasamente comprendido, y mucho menos reconocido, por lo que cuenta con escaso apoyo institucional, estando más bien en grave riesgo (Nussbaum, 2008: 479-480; 2010).

Pero reconocer este papel a las artes y humanidades tendrá una consecuencia pública trascendente, pues implicará asumir que tienen una función política vital, al cultivar habilidades imaginativas que resultarán fundamentales para el desarrollo de la vida pública, al formar ciudadanos más críticos y comprometidos con la justicia. En suma, del cultivo de las emociones, que las humanidades tienen encomendado, dependerá en gran medida la viabilidad de un proyecto de sociedad y ciudadanía más crítica y justa. De manera que aquellas jugarán un papel crucial en el desarrollo, profundización y estabilización de la democracia (Nussbaum, 2010: 51-74, 162-189; Gil, 2016b). 


\section{LA COMPASIÓN TRÁGICA Y LA BÚSQUEDA DE UN NUEVO MODELO DE JUSTICIA}

Todo cuanto venimos diciendo sobre emociones, educación y política forma parte del proyecto nussbaumsiano de reformular una teoría de la justicia que vaya más allá de las limitaciones que presentan las teorías del contrato (Nussbaum, 2007b). Nussbaum reconoce que las teorías de la justicia social deben ser abstractas, pero, al mismo tiempo, tienen que ser capaces de afrontar los nuevos desafíos. En este sentido, las teorías tradicionales de la justicia son bastante deficitarias con relación al problema de la igualdad de género, o de las personas con discapacidades físicas y mentales. Además, los problemas de justicia, en un mundo global, no pueden plantearse en el estrecho marco del Estado-nación, sino en el contexto de interacciones propio de un mundo globalizado. Por último, una teoría de la justicia también tendría que hacerse cargo del trato que dispensamos a los animales no humanos. Así pues, el enfoque del contrato social, basado en la cooperación social y el beneficio mutuo, tendría que ser repensado, no para abandonarlo, sino para ampliarlo (Nussbaum, 2007b: 182-184). Rawls se esforzó en reelaborarlo, en cierto modo, dotándolo de una gran profundidad psicológica, y combatiendo al mismo tiempo el enfoque utilitarista de la justicia. Sin embargo, el propio Rawls reconocía que los tres problemas apuntados resultan muy difíciles de abordar desde una concepción contractualista de la justicia (Nussbaum, 2007b: 34-44).Y para Nussbaum, se trata de problemas que aún no han sido resueltos, y que exigen una noción plural del sujeto de justicia (Tienda, 2010). Pero para intentarlo, necesitamos repensarnos a nosotros mismos de un modo bien distinto a como lo venían haciendo las teorías del contrato. Y no es este un problema meramente académico, sino que tendrá un enorme impacto en nuestras vidas:

Ninguno es meramente académico. Las doctrinas del contrato social tienen una influencia amplia y profunda en nuestra vida política. La imagen que tenemos de quiénes somos y por qué vivimos juntos configura nuestras ideas sobre los principios políticos que deberíamos elegir y las personas que deberían participar en su elección. La idea corriente de que algunos ciudadanos «pagan su parte» y otros no, de que algunos ciudadanos son parásitos y otros son «normalmente productivos», traduce al nivel de la imaginación popular la idea [de] que la sociedad es un mecanismo de cooperación orientado al beneficio muto (Nussbaum, 2007a: 29).

Así pues, frente a las insuficiencias del modelo del contrato, que llega hasta Rawls, propondrá Nussbaum el enfoque de las capacidades, donde serán estas el eje central de la justicia, y no la idea del beneficio mutuo. 
Solo desde tal perspectiva, sin que ello implique el abandono de las tesis contractualistas (Tienda, 2011: 324-331), podremos superar una idea de justicia que es incapaz de afrontar los nuevos problemas a los que nos hemos referido.Y en este sentido, será esencial el trabajo que han de realizar las humanidades, desde el ámbito del cultivo ciudadano de las emociones. No olvidemos que una nueva teoría de la justicia tendría que incluir a los discapacitados, a los dependientes, a los pobres - personas y naciones-, y a los animales no humanos. En suma, tendría que ampliar el esquema tradicional del contrato, basado en el beneficio mutuo, hacia un nuevo modelo de justificación y concienciación, centrado en las capacidades y el desarrollo humano, que se haga plenamente cargo de nuestra finitud y vulnerabilidad a lo largo de una vida (Nussbaum, 2002; 2007b: 82-106).

Pero -y esto deberíamos tenerlo muy presente- ninguna teoría de la justicia podrá llevarse a la práctica si no hay ciudadanos que estén dispuestos a admitirla y a trabajar por ella. Y de aquí la importancia de cultivar y cuidar el sentimiento moral, las emociones que favorecen el florecimiento humano, y, finalmente, darle el respaldo institucional necesario, reclamando la presencia de las humanidades en todos los niveles educativos, para dar viabilidad, profundidad y estabilidad al proyecto democrático (Nussbaum, 2010), centrado en una más amplia e inclusiva concepción de la justicia (Nussbaum, 2007b).

Por otra parte, reconocerá Nussbaum que la tradición contractualista tenía sus ventajas: no dependía de la benevolencia, y no exigía su generalización, pues le bastaba el beneficio mutuo (Nussbaum, 2007a: 32). Hobbes, Hume, Locke y Kant, cada uno a su manera, no confiaban excesivamente en el poder efectivo de la benevolencia. Pero Rawls se dará perfecta cuenta de la importancia de cuidar lo que entraría dentro de la psicología política, es decir, el cultivo público del sentimiento, para dotar de estabilidad a la sociedad bien ordenada. Las instituciones juegan, en tal sentido, un papel inexcusable. También lo cree Nussbaum, solo que su enfoque irá más allá del rawlsiano, pues se centrará en el concepto y promoción de las capacidades humanas como núcleo de su propuesta de justicia (Nussbaum, 2007b: 163-184; 2014a). Pero será aún más exigente, al incorporar como necesaria una nueva paideia, una educación pública de la compasión, ya que insistirá en que podemos tener la teoría, y podemos, incluso, verla reconocida y plasmada en el plano institucional, pero, finalmente, todo podría desplomarse si descuidamos el factor humano, el factor educativo, aquel que posibilita que todo esto acabe impregnando real y substancial- 
mente a la ciudadanía, materializándose en la práctica, y dotando de estabilidad al proyecto (Nussbaum, 2007a: 33-35).

El Emilio de Rousseau, La teoría de los sentimientos morales (A. Smith), y La utilidad de la religión (J. S. Mill) son perspicaces ejemplos de la importancia del cultivo de las emociones favorables al cambio social radical, en la dirección de la justicia y la igualdad de la dignidad. Como C. D. Batson confirmará, las personas que oyen un relato de las dificultades de otra, experimentan compasión y elaboran planes de ayuda (Batson, 1991; Nussbaum, 2007a: 33-34). Y de aquí el importantísimo papel educativo a desempeñar por las humanidades respecto a las emociones, evitando distraernos de tal objetivo. En tal sentido, considera Nussbaum que nuestro material constitutivo básico es más roussoniano que hobbesiano, si bien tenemos que alcanzar adecuadamente la conciencia del sufrimiento del otro. El problema, entonces, estribará en cómo la educación liberal puede cultivar sentimientos que complementen y ayuden al enfoque de las capacidades (Nussbaum, 2007b; 2010).

La propia Nussbaum cree, en tal sentido, que hay mucha tarea por hacer, pues necesitamos impulsar un importante trabajo educativo en la dirección de la benevolencia.Y, sin embargo, Nussbaum lamentará que la cultura general de los Estados Unidos esté yendo en la dirección opuesta, al fomentar la idea falsa de un «hombre de verdad», duro y autosuficiente, que contrasta con nuestra humana vulnerabilidad. De aquí la importancia de destacar ejemplos de lo que sería una retórica pública adecuada, como la que encontramos en F. D. Roosevelt, al referirse a los pobres como ciudadanos con dignidad; o a Martin L. King, sobre la igualdad racial y ciudadanía mundial.Y por ello, creemos que el de Nussbaum es un enfoque filosófico y político sobre la justicia, que, junto al mérito de revisar el modelo de la tradición del contrato hasta Rawls, se ha esforzado tenazmente en hacernos comprender que el proyecto de una sociedad democrática más justa y estable depende, en su realizabilidad, de la educación humanística como factor clave (Nussbaum, 2007a: 33; 2010).

Resultará, pues, esencial revisar la imagen que tenemos de nosotros mismos, lo que nos llevará también a modificar nuestra mirada sobre el otro (Nussbaum, 2010).Y a tal respecto, jugarán un papel esencial la filosofía y la literatura, logrando un equilibrio perceptivo, determinante para la deliberación pública (Nussbaum, 1995a; 2010; 2014b;Tienda, 2015). Pero la imagen que tenemos de nosotros mismos, en la tradición contractualista, tiene unos orígenes históricos concretos. Y de aquí la importancia de matizar nuestra propia comprensión como seres finitos, vulnerables, expues- 
tos a las contingencias, y no autosuficientes. En tal sentido, se hace patente la importancia de cultivar sentimientos que favorezcan la benevolencia y el florecimiento - eudaimonía- de todos los seres humanos. De manera que, por sintetizarlo, el problema de una sociedad más justa tendría tres ejes: uno, más abstracto, de construcción filosófica de la teoría; otro, político-institucional, donde aquel modelo cobra realidad, y otro, aunque no menos importante, educativo, pues será de las personas de quien dependerá, en última instancia, la realizabilidad de tal modelo. En suma, necesitamos que la teoría, las instituciones y la educación vayan más allá de la concepción de un sujeto y de una sociedad en términos meramente contractuales. Por ello, mientras no cambiemos nuestra propia comprensión del yo y de la sociedad, toda propuesta diferente de justicia parecerá utópica, irrealizable, (Nussbaum, 2007a: 34).

Nussbaum muestra, sobradamente, cómo una concepción institucional de la tolerancia, sostenida por Locke, Kant y Rawls, resultará insuficiente, pues para su viabilidad y efectividad tampoco bastará con asegurarla en dicho plano, sino que las personas tendrán que interiorizarla mediante un aprendizaje moral basado en el respeto y la dignidad. Esto supondrá reconocer, necesariamente, el papel de las emociones en el interior de la concepción de lo político, sin poner en peligro la neutralidad liberal (Nussbaum, 2014a: 30-32), aunque ello no esté exento de problemas (Lariguet, 2015: 107-111). Y esto implicará diseñar estrategias educativas y públicas para contrarrestar los prejuicios y la intolerancia, así como las relaciones jerárquicas en la educación de los niños, y hacerlo de forma que sea accesible psicológicamente, con un contenido sencillo y comprensible. Y al mismo tiempo, la educación deberá estar orientada a fortalecer la crítica y la expresión respetuosa del disenso (Nussbaum, 2014a: 27-32). En tal sentido, el papel educativo de las humanidades, orientado al cultivo de las emociones, constituirá un elemento inexcusable para ensanchar y reforzar nuestra racionalidad práctica, que tendrá que arrostrar problemas cada vez más complejos en sociedades donde la pluralidad es un hecho insoslayable. Aprender a convivir con quien tiene una cultura, ideas religiosas o políticas muy distintas de las nuestras, así como cuidar de todas aquellas problemáticas que derivan de nuestra humana vulnerabilidad y exposición a la desgracia, resultará labor ineludible, si aspiramos a convertir nuestras sociedades democráticas en espacios públicos de concordia y de justicia. Las humanidades en general, pero la filosofía y la literatura en particular - como otrora los festivales trágicos - desempeñarán un papel decisivo e inexcusable en la formación de una racionalidad práctica acorde con esta 
interpretación de lo humano, así como en la construcción del proyecto de un humanismo cívico cosmopolita (Nussbaum, 1999: 13-29; Modzelewski, 2014).

En suma, el enfoque nusbaumsiano sobre emociones y educación viene a recordarnos lo que ya nos advertiría Platón en el Protágoras, al referirnos el mito de Prometeo: que los saberes científico y técnico - herramientas y fuego- no bastan para la construcción de la ciudad, pues si los hombres carecen de aidos - pudor- y díke -justicia- acabarán despedazándose los unos a los otros (Platón, 1993: 320c-322d). Por ello, no podemos perder de vista que, como Nussbaum ha venido insistiendo, todo ideal político está sustentado por sus propias emociones características (Nussbaum, 2014b: 143). Y en tal sentido, inspirándose en el modelo de racionalidad práctica aristotélico (González, 2007; Trueba, 2009b), Nussbaum ha propuesto una concepción de la justicia centrada en la democracia, la dignidad, las capacidades y el desarrollo humano, que vendría a completar y subsanar las deficiencias del enfoque contractual, cuyo eje era el beneficio mutuo, y cuyas limitaciones ha discutido Nussbaum ampliamente (Nussbaum, 2007b).Y en la propuesta nussbaumsiana, que gravita sobre el pleno desarrollo humano, vertebrado en la dignidad, y flanqueado por la humana finitud y vulnerabilidad, ha quedado sobradamente puesto en valor el insoslayable papel que han de jugar las humanidades en la educación y el cultivo de las emociones, si es que aún queremos tomar en serio la viabilidad de tal propuesta, con todo lo que con ella está en juego para la desgracia y felicidad humanas.

\section{BIBLIOGRAFÍA}

Aristóteles (1990). Retórica. Madrid: Gredos (Quintín Racionero, trad.). Arendt, Hannah (2003). Eichmann en Jerusalén. Barcelona: Lumen. Arteta,Aurelio (1996). La compasión, apología de una virtud bajo sospecha. Barcelona: Paidós.

Batson, Daniel (1991). The Altruism Question: Toward a Social-Psycological Answer. Hillsdale: N.J., Lawrence Erbaum Associates.

Boruah, Bijoy (1988). Fiction and Emotion. Oxford: Clarendon Press. Bejarano, Teresa (1995). Las emociones ante la ficción. Thémata. Revista de Filosofía, 13, 73-95.

Benéitez, José Javier (2010). La ciudadanía cosmopolita de M. Nussbaum. Daímon. Revista Internacional de Filosofía, suplemento 3, 347-354. 
Conill, Jesús (2009). Por una economía hermenéutica de la pobreza. En Cortina, Adela \& Pereira, Gustavo (eds.). Pobreza y libertad. Erradicar la pobreza desde el enfoque de Amartya Sen (151-162). Madrid:Tecnos.

Cortina, Adela (2010).Justicia cordial. Madrid:Trotta.

Di Tullio, Anabella (2013). ¿Hacia una justicia sin fronteras? El enfoque de las capacidades y los límites de la justicia. Daimon, Revista Internacional de Filosofía, 58, 51-68.

Gil, Marta (2013). La repugnancia: de reacción fisiológica a emoción política. Recerca. Revista de Pensament i Anàlisi, 13, 137-152.

Gil, Marta (2014). La teoría de las emociones de Martha Nussbaum: el papel de las emociones en la vida pública. Tesis doctoral. Facultad de Filosofía y Ciencias de la Educación. València: Universitat de València.

Gil, Marta (2016a). La complejidad de la experiencia emocional humana: emoción animal, biología y cultura en la teoría de las emociones de Martha Nussbaum. Dilemata, 21, 207-225.

Gil, Marta (2016b). El cultivo de las humanidades y las emociones: reflexiones en torno a la educación moral y política. Pensamiento. Revista de Investigación e Información filosófica, 72, 274. doi: http://dx.doi. org/10.14422/pen.v72.i274.y2016.004.

González Esteban, Elsa (2007). Una lectura actualizada de la ética aristotélica. La mirada de Martha Nussbaum. Quaderns de Filosofia $i$ Ciència, 37, 91-100.

Jahanbegloo, Ramin (1993). I. Berlin en diálogo con Ramin Jabanbegloo. Madrid:Anaya, \& Mario Muchnik. (M. Cohen trad.).

Lariguet, Guillermo (2015). Un estudio crítico de Political emotions de Martha Nussbaum. Crítica. Revista Hispanoamericana de Filosofía, 47(141), 95-218.

Lotman, Yuri (2011). Estructura del texto artístico. Madrid:Akal.

Mèlich, Joan-Carles (2010). Ética de la compasión. Barcelona: Herder.

Modzelewski, Helena (2014). Autorreflexión y educación de las emociones para la democracia. Areté. Revista de Filosofía, XXVI(2), 315-333.

Monereo Atienza, Cristina (2015). Martha C. Nussbaum - Otro enfoque para la defensa del ser humano y de los derechos de las mujeres. Seqüência (Florianópolis), 70, 93-114. doi: http://dx.doi.org/10.5007/2177-7055 .2015v36n70p93.

Nussbaum, Martha Craven (1995a). La imaginación literaria en la vida pública. Isegoría, 11, 42-80.

Nussbaum, Martha Craven (1995b). La fragilidad del bien. Fortuna y ética en la tragedia y la filosofía griega. Madrid:Visor (A. Ballesteros trad.). 
Nussbaum, Martha Craven (1997b). Capabilities and Human Rights. Fordham Law Review, 66, 273-300.

Nussbaum, Martha Craven (1999). Patriotismo y cosmopolitismo. En Nussbaum, Martha \& Cohen, Joshua. Los límites del patriotismo. Identidad, pertenencia y ciudadanía mundial (13-29). Barcelona: Paidós.

Nussbaum, Martha Craven (2001). El cultivo de la bumanidad. Una defensa clásica de la reforma en la educación liberal. Barcelona: Paidós.

Nussbaum, Martha Craven (2002). Las mujeres y el desarrollo bumano: el enfoque de las capacidades. Barcelona: Herder.

Nussbaum, Martha Craven (2003). Capabilities as fundamental entitlements: Sen and Social Justice. Feminist Economics 9, 33-59.

Nussbaum, Martha Craven (2006). El ocultamiento de lo bumano. Repugnancia, vergüenza y ley. Buenos Aires: Katz Editores. (G. Zadunaisky trad.).

Nussbaum, Martha Craven (2007a). Los sentimientos morales y el enfoque de las capacidades. Claves de Razón Práctica, 169, 28-35.

Nussbaum, Martha Craven (2007b). Las fronteras de la justicia: consideraciones sobre la exclusión. Barcelona: Paidós.

Nussbaum, Martha Craven (2008). Paisajes del pensamiento. La inteligencia de las emociones. Barcelona: Paidós Ibérica.

Nussbaum, Martha Craven (2010). Sin fines de lucro. Por qué las democracias necesitan de las humanidades. Buenos Aires: Katz Editores.

Nussbaum, Martha Craven (2011). Perfectionist Liberalism and Political Liberalism. Pbilosopby and Public Affairs, 39, 3-45.

Nussbaum, Martha Craven (2013). La nueva intolerancia religiosa. Cómo superar la política del miedo en una época de inseguridad. Barcelona: Paidós. (A. Santos, trad.).

Nussbaum, Martha Craven (2014a). Una revisión de Liberalismo político de Rawls. Derecho del Estado, 32, Universidad Externado de Colombia, enero-junio, 5-33.

Nussbaum, Martha Craven (2014b). Emociones políticas. ¿Por qué el amor es importante para la justicia? Barcelona: Paidós. (A. Santos, trad.).

Platón (1993). Diálogos (vol. I). Madrid: Gredos.

Radford, Colin (1975). How can we be moved by the fate of Anna Karenina? Proceeding of the Aristotelian Society, LXIX, 67-80.

Scruton, Roger (1974). Art and Imagination. Londres: Mehuen \& Co.

Tienda, Lidia (2010). La noción plural de sujeto de justicia. Un nuevo reto para la filosofía. Daimon. Revista Internacional de Filosofía, suplemento $3,171-179$. 
Tienda, Lidia (2011). El modelo de racionalidad de Martha C. Nussbaum: emociones, capacidades y justicia. Tesis doctoral. Facultad de Filosofía y Ciencias de la Educación. València: Universitat de València.

Tienda, Lidia (2015). El papel de las emociones y la literatura en la deliberación pública: la figura del equilibrio perceptivo de Martha Craven Nussbaum. Arbor, 191(773) 3001. doi: http://dx.doi.org/10.3989/ arbor.2015.773n3011.

Trueba, Carmen (2004). Ética y tragedia en Aristóteles. Barcelona/México: Anthropos.

Trueba, Carmen (2009a). Una aproximación al cosmopolitismo de M. C. Nussbaum. En Granja, Dulce María, \& Leyva, Gustavo (eds.) (2009). Cosmopolitismo. Democracia en la era de la globalización (181-204). Barcelona:Anthropos.

Trueba, Carmen (2009b). La teoría aristotélica de las emociones. Signos Filosóficos, XI(22), 147-170.

Walton, Kendall (1978a). Fearing Fictions. Journal of Philosophy, LXXXV, 5-27.

Walton, Kendall (1978b). How remote are fictional worlds from the real world.Journal of Aesthetics and Art Criticism, XXXVII, 11-23. 